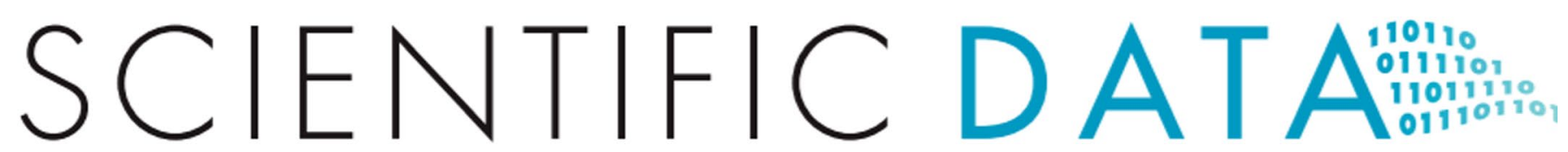

\title{
OPEN Author Correction: A compendium of geochemical information from the Saanich Inlet water column
}

\author{
Mónica Torres-Beltrán ${ }^{1}$, Alyse K. Hawley ${ }^{1}$, David Capelle ${ }^{2}$, Elena Zaikova ${ }^{3}$, David A. Walsh ${ }^{4}$, \\ Andreas Mueller ${ }^{1}$, Melanie Scofield ${ }^{1}$, Chris Payne ${ }^{2}$, Larysa Pakhomova ${ }^{2}$, Sam Kheirandish ${ }^{1}$, \\ Jan Finke ${ }^{2}$, Maya Bhatia ${ }^{1}$, Olena Shevchuk ${ }^{1}$, Esther A. Gies ${ }^{5}$, Diane Fairley ${ }^{1}$, Céline Michiels ${ }^{1}$, \\ Curtis A. Suttle ${ }^{1,2,6}$, Frank Whitney ${ }^{7}$, Sean A. Crowe ${ }^{1,2,8}$, Philippe D. Tortell ${ }^{2,6,9}$ \& \\ Steven J. Hallam ${ }^{1,8,9,10,11}$
}

Correction to: Scientific Data https://doi.org/10.1038/sdata.2017.159, published online 31 October 2017

In Table 3 of this Data Descriptor the units of Mean_N $\mathrm{N}_{2} \mathrm{O}$ and $\mathrm{Mean} \_\mathrm{CH}_{4}$ are incorrectly stated as "Nanomolar $(\mu \mathrm{M})$ ". This should instead read "Nanomolar (nM)".

(c) (i) Open Access This article is licensed under a Creative Commons Attribution 4.0 International License, which permits use, sharing, adaptation, distribution and reproduction in any medium or format, as long as you give appropriate credit to the original author(s) and the source, provide a link to the Creative Commons license, and indicate if changes were made. The images or other third party material in this article are included in the article's Creative Commons license, unless indicated otherwise in a credit line to the material. If material is not included in the article's Creative Commons license and your intended use is not permitted by statutory regulation or exceeds the permitted use, you will need to obtain permission directly from the copyright holder. To view a copy of this license, visit http://creativecommons.org/licenses/by/4.0/.

(C) The Author(s) 2019
${ }^{1}$ Department of Microbiology and Immunology, University of British Columbia, Vancouver, British Columbia, V6T 1Z3, Canada. ${ }^{2}$ Earth, Ocean and Atmospheric Sciences, University of British Columbia, Vancouver, British Columbia, V6T 1Z4, Canada. ${ }^{3}$ Department of Biology, Georgetown University, Washington, DC, 20007, USA. ${ }^{4}$ Department of Biology, Concordia University, Montreal, Quebec, H4B 1R6, Canada. ${ }^{5}$ Department of Civil Engineering, University of British Columbia, Vancouver, BC, V6T 1Z4, Canada. ${ }^{6}$ Department of Botany, University of British Columbia, Vancouver, British Columbia, V6T 1Z4, Canada. ${ }^{7}$ Department of Fisheries and Oceans Canada, Sidney, British Columbia, V9L 6V9, Canada. ${ }^{8}$ ECOSCOPE Training Program, University of British Columbia, Vancouver, British Columbia, V6T 1Z4, Canada. ${ }^{9}$ Peter Wall Institute for Advanced Studies, University of British Columbia, British Columbia, V6T 1Z2, Canada. ${ }^{10}$ Genome Science and Technology Program, University of British Columbia, Vancouver, BC, V6T 1Z4, Canada. ${ }^{11}$ Graduate Program in Bioinformatics, University of British Columbia, Vancouver, British Columbia, V6T 1Z4, Canada. Mónica Torres-Beltrán and Alyse K. Hawley contributed equally. Correspondence and requests for materials should be addressed to S.J.H. (email: shallam@mail.ubc.ca) 